International Journal of Instruction e-ISSN: 1308-1470 • www.e-iji.net
July $2020 \bullet$ Vol.13, No.3

p-ISSN: 1694-609X

pp. $187-206$

Received: 21/06/2019

Revision: 11/01/2020

Accepted: $15 / 01 / 2020$

OnlineFirst:12/04/2020

\title{
The Effect of a Dual Coding Technique on Idiom Interpretation in ESL/EFL Learners
}

\author{
Denis Samburskiy
}

$\mathrm{PhD}$, Syracuse University, USA, dsamburs@syr.edu

$\mid$

The goal of this study is to examine differences in the interpretation of idioms by EFL learners in Russia and ESL learners living in the USA and analyze a facilitative effect of a dual-coding technique on interpretation of unfamiliar idioms. Firstly, the study investigates an impact that different levels of metaphorical competence may have on interpretation of target idioms. Secondly, the study investigates whether an elucidation technique, which includes a mapping of the literal meaning of target idioms on correct figurative meaning, facilitates the interpretation of unfamiliar idioms. The study concluded that learners with lower levels of metaphorical competence were more likely to interpret idioms literally. In addition, although the technique proved to be effective for all levels, learners with lower levels of metaphorical competence benefited more from the dual-coding technique. Some implications for language educators are discussed.

Keywords: idiom comprehension, dual-coding theory, literal and figurative meaning, metaphoric competence, cognitive linguistics

\section{INTRODUCTION}

The knowledge of idiomaticity plays a crucial role in language proficiency (Lantolf \& Thorne, 2006). As Lantolf (1999) aptly argued, "A knowledge of shared cultural references is necessary [...] to understand and produce the target language with any degree of accuracy." Kecskes and Papp (2000) claim that for language learners to be native-like, 'they have to learn to think as native speakers do, perceive the world the way native speakers do, and use the language metaphorically as native speakers do' ( $\mathrm{p}$. 9). Linguists define this native-like metaphorical skill as 'conceptual fluency', with 'metaphorical competence' being part of it (Danesi, 2003, 1993; Kecskes, 2000; Littlemore \& Low, 2006). In his Conceptual Fluency Theory, Danesi (1998) posits that every language is founded on a conceptual system which supports both language and cognitive functioning. For Kecskes and Papp (2000), conceptual fluency is the knowledge of 'how the target language reflects and encodes its concepts on the basis of metaphorical structuring and other cognitive mechanisms' (p. 10). This vital knowledge, according to the authors, is precisely the ground for the assumption that foreign

Citation: Samburskiy, D. (2020). The Effect of a Dual Coding Technique on Idiom Interpretation in ESL/EFL Learners. International Journal of Instruction, 13(3), 187-206. https://doi.org/10.29333/iji.2020.13313a 
language learners must spend a considerable time in the target language community to sound 'authentic.'

Despite its ubiquity in daily communication between native speakers, idiomatic language is notoriously difficult to teach and learn in EFL and ESL classrooms (Irujo, 1986; Danesi, 2003; Littlemore, 2010; Chen \& Lai, 2013; Rizq, 2015). If conceptual fluency is of paramount importance for effortless native-like communication (in speaking (Liu, 2003) and writing (Kathpalia \& Carmel, 2011; Hoang \& Boers, 2018), L2 instruction should further the learning and development of this skill through the incorporation of idiomatic language into classroom discourse. The cognitive linguistic view of language suggests that the meaning of many idioms is not arbitrary, but rather motivated by three mechanisms, namely metaphor, metonymy and conventional knowledge (Kövecses, 2002, 2005, 2010, 2015; Lakoff \& Johnson, 1980; Gibbs, 2006). 'Motivated meaning', a central concept in cognitive linguistics, is based on the assumption that the meaning behind all metaphoric language derives from people's knowledge of and embodied experience with their physical environment. Embodiment refers to the way the human body affects and directs our understanding and cognition (Gibbs, 2006). Since metaphorical meaning of many idioms is rooted in human knowledge of the concrete physical world around them, the learning of this meaning could and should be facilitated by concrete concepts.

This study examines the role of metaphorical competence in the interpretation of English idioms by non-native speakers (NNSs) learning English in EFL and ESL environments. Based on the previous research (Cieślicka, 2006; Abel, 2003; Kecskes, 2000), the first hypothesis of this study is that English learners whose level of metaphorical competence is lower will have literal meaning of idioms as salient when target idioms are presented without contextual support. Secondly, the study includes an experiment which tests a dual-coding technique that combines verbal and visual information to facilitate comprehension of idiomatic expressions. All groups of participants are expected to benefit from this technique, regardless of their levels of metaphorical competence and language learning backgrounds (EFL or ESL). The following research questions guide this study:

1. How will the disparity in the participants' language learning experiences (EFL or ESL) and levels of metaphorical competence affect their interpretation of unfamiliar idioms?

2. Will a dual-coding technique prove to be facilitative in interpretation of unfamiliar English idioms?

\section{THEORETICAL UNDERPINNINGS}

\section{Idiom Interpretation and Salience}

Native speakers (NSs) generally view idiomatic expressions holistically, often without realizing that those expressions are figurative (Wray, 1999, 2000; Schmitt, 2000; Conklin \& Schmitt, 2012). This holistic, noncompositional approach is the result of the natural acquisition of idioms in context-rich environments. Since language learners do not have access to such environments, they have to process idiomatic language 
analytically - determining the meaning from separate components. This usually has a misleading effect because, by definition, the meaning of most idioms does not consist of the meaning of their parts.

Cognitive development of speakers and their experiential knowledge may make the lexical meaning of certain figurative expressions easily comprehensible either because an equivalent exists in their L1 or because that meaning is contingent on the literal sense. When this contingency is obscured, the connection between the idiom's concrete and figurative senses becomes feeble, if not nonexistent (this results in so-called frozen or dead metaphors). Some researchers suggest that language learners are prone to rely on the literal meaning of figurative language and on their L1 conceptual system because they lack good metaphorical competence in L2 (Kecskes, 2000, 2001, 2006, 2010; Abel, 2003). Such literal meanings are first to be accessed due to their availability in the speaker's conceptual system.

This availability is discussed at length in Giora's (1997) seminal work on Graded Salience Hypothesis. Giora (1997) argues that 'the salient meaning of a word or an expression is its lexicalized meaning, i.e., the meaning retrievable from the mental lexicon rather than from the context.' Giora posits that cognitively prominent meanings are placed higher in the hierarchy of meanings of a lexical item (1999). The prominence can be so powerful that even context fails to override it. In addition, Giora claimed that rather than accessing the context-compatible information first, our mind opts for the promptly available information. This indicates that for NSs the figurative meaning of idioms is the first to be accessed (regardless of context); therefore, it is salient. However, for NNSs it is less salient, that is why they need to activate the entries for each constituent of the idiom (i.e. decompose it) to access its meaning. The experience of NSs and NNSs with the target language is undoubtedly different; consequently, 'what is salient for individuals belonging to the target language community will not necessarily be salient for the "newcomers," the L2 learners' (Kecskes, 2001, p. 3). The reason is, NNSs are not able to live through the same linguistic and socio-cultural experience that encodes salient meanings in NSs' minds.

When encountering an L2 figurative expression, a NNS relies primarily on the salience accrued via his/her experience with the linguistic expression, which is often at odds with that of the L1 language community's. While processing an English idiom, for instance, the prominence may be given to a metaphorical sense that may coincide in L1 and L2 (e.g., English thick-skinned and Russian толстокожий) and, therefore, make sense in the given context. If L1 transfer does not yield a sensible outcome, a NNS may process the constituents of an idiom literally, thus, attempting to make sense of the expression by analyzing the meaning of its parts. Exceptions, of course, are those NNSs who have spent a considerable time in the target language environment and have had access to the preferred ways of using figurative language by the NS community. Hence it is sensible to hypothesize that the NNS's compositional meaning of figurative expressions becomes modified to reflect the concomitant correct figurative sense prevailing in the target language. 


\section{The Dual-Coding Theory}

The principal goal of this study is to test a technique that would utilize the concrete literal meaning of certain idioms to facilitate the comprehension of their correct figurative meaning. The theoretical foundation for this technique is based on Paivio's dual-coding theory $(1971,1986)$.

The dual-coding theory posits that the human cognition 'has become specialized for dealing simultaneously with language and with nonverbal objects and events' (Paivio, 1986, p. 53). According to Paivio, cognition involves two distinct but constantly interacting subsystems (verbal and nonverbal). The systems are composed of representational units, called logogens (for verbal information) and imagens (for visual information). Both systems are activated when we process or retrieve information - in verbal and visual form. Paivio's main claim is that verbal system never operates by itself but is always facilitated by the nonverbal imagery system. He argues that imagery is a powerful facilitator of memory and cognition. Therefore, employing both verbal and visual pathways could facilitate the interpretation and retention of idiomatic language, which was already demonstrated in some studies (Boers et al., 2009; Cuevas, 2016; Sadoski, 2005; Sadoski \& Paivio, 2013).

One problem, however, is that not all idioms can be easily associated with an image. Imageability is described as a property of a word or concept reflecting how easy or difficult it is to visually or acoustically imagine (Hamilton \& Rajaram, 2001; Boers \& Lindstromberg, 2012). According to the dual-coding theory, whereas concrete and abstract words are represented in the verbal system, only concrete words are linked to the imaginal system, i.e. imaginable. Since images provide an additional means of storing and retrieving concrete words, these words tend to be recalled better than abstract words that lack any support in the imaginal system. In many experimental studies, Paivio and his associates demonstrated beneficial effects of imagery on learning and memory (e.g., Paivio, 1971; Paivio \& Csapo, 1973; Paivio et al., 1968). Researchers have demonstrated that imagery and language comprehension are closely related processes, particularly in concrete words (Begg \& Paivio, 1969; Paivio \& Begg, 1970; Yuille \& Paivio, 1969; Marian \& Spivey, 2003; Spivey \& Marian, 1999). The notion of imageability is implemented in the selection of idioms for the dual-coding elucidation technique.

Cognitive linguistics researchers appropriated the tenets of the dual-coding theory to examine facilitative effects of visual information on cognition. Boers et al. (2004) and Boers et al. (2007) developed an etymological elaboration technique that similarly employed the dual-coding theory to enhance learners' comprehension and retention of idiomatic expressions. Their findings, along with a few other studies (e.g. Aydin, 2017; Boers, 2000; Boers et al., 2009; Csábi, 2004; Verspoor \& Lowie, 2003), demonstrated encouraging results regarding learners' ability to interpret figurative senses of polysemous words based on their literal senses. In addition, Boers and Lindstromberg (2008) surveyed a number of studies and contended that connecting figurative senses of idioms with their literal ones could indeed be a pedagogically effective technique for language learners. 
This study does not aim to elucidate idioms' etymological origin or conceptual metaphoric foundation but instead to appeal to the concrete knowledge of the world shared by the participants to facilitate the understanding of certain imageable English idioms. Because the properties of observable objects in the world are recognizable by speakers of all human languages, the study employs these properties in the dual-coding elucidation technique to help the learners establish a connection between these physical properties and abstract figurative meanings of idioms.

\section{Participants}

To address the research questions of this study, two cohorts of English language learners were involved: one from the United States (ESL) and one from Russia (EFL). The focus was on language learners who had attained intermediate levels of proficiency or higher because these learners were more likely to have a good knowledge of English idiomatic language; hence, their levels of metaphorical competence should be higher than those of beginning learners.

The ESL cohort comprised adult learners of English in an evening ESL course provided by an American university. Altogether, 58 ESL learners participated in the study: 34 spoke Spanish as their mother tongue, 12 spoke German, 6 spoke Korean, 5 spoke Mandarin, and 1 spoke Arabic. The ESL participants were grouped into a similar proficiency level based on the results of a placement test given prior to the beginning of the ESL program. The placement test consisted of a grammar test, a written task, and an oral story-telling task based on a series of pictures. Only the learners who received at least a grade B for each part of the test were included in the study.

The EFL cohort comprised 57 English learners enrolled full time in courses at a university in Russia. The mother tongue of all EFL participants was Russian. These students were admitted to the university on the basis of an English proficiency test administered to high-school seniors throughout the country. Their matriculation implied that each student had intermediate proficiency levels or higher. However, to ensure that EFL participants were similar to ESL participants in their proficiency, the same test was administered. Similarly, only the learners who received at least a grade B for each part of the test were included in the study.

\section{METHOD}

Since the participants' learning environment is an important variable in this study, all the ESL and EFL participants were asked to report an approximate amount of time they typically spent interacting with native English speech (texts, conversation, audio podcasts, etc.). It is an important variable to take into account because a large amount of language knowledge comes from noticing various expressions in appropriate contexts of use (Ellis, 1999; Schmidt, 1990). Moreover, a number of studies demonstrated a link between an experience of studying abroad and general improvements in language proficiency (Freed, 1995; Llanes \& Muñoz, 2009). Consequently, it was hypothesized that English learners who engage in meaningful interactions with native English speakers and/or are surrounded by English media (newspapers, magazines, websites, 
television, etc.) on a daily basis may have a better chance to develop a sound grasp of authentic nonliteral language, at least at the level of comprehension.

In contrast, EFL learners often lack the adequate amount of authentic interaction with native speakers, and the amount of time spent reading or listening to quality authentic media is minimal due to the absence of any functional value in it. This may have an adverse effect on the development of the learners' metaphorical competence and L2 conceptual fluency in general. As a result, EFL learners may often rely on literal meanings of lexemes and lexical expressions or their L1 counterparts, which results in negative transfer (Boers \& Demecheleer, 2001; Charteris-Black, 2002; Littlemore, 2001).

All the ESL participants indicated that they had spent at least 6 months in the USA. Despite the fact that some ESL learners had been living in America for over 5 years, their proficiency was not necessarily very high (one of the reasons they were attending the evening ESL classes). This, however, does not mean that these learners had not developed a good understanding of L2 idioms simply by virtue of being immersed in L2 on a daily basis. In turn, most EFL participants stated that they had never been abroad, with only two individuals having visited English-speaking countries for very short periods of time (around 2 weeks). This could put them in a disadvantaged position regarding their metaphorical competence, compared to their ESL counterparts.

\section{Questionnaire}

The questionnaire consisted of several sections. SECTION 1 included a consent form, which asked each participant if they agreed to be in the study. This part, as well as all the other parts of the questionnaire, was mandatory so no respondent could skip it. The section also included some background questions: the mother tongue of the respondent and how many hours a week (approximately) the respondent communicated with NSs of English or watched/read/listened to authentic content in English, and the approximate amount of time spent in an English-speaking country.

SECTION 2 of the questionnaire included metaphorical competence assessment and comprised three tasks. Task 1 included a text adapted from Milton and Evans' textbook A Good Turn of Phrase: Advanced idiom Practice (2000). The text that was picked for this part of the questionnaire had 10 common idiomatic expressions. All participants were asked to paraphrase or explain the meaning of each idiom in the spaces provided. Examples of idioms from the text include a small fortune, mean business, bear fruit, money down the drain, etc. Task 2 contained five sentences, each of which was followed by three paraphrases containing idioms. Only one paraphrase had a meaning similar to the original sentence, and the participants were asked to identify the correct paraphrase for each sentence. For example, if the original sentence was 'Your idea is right up my alley,' the three paraphrases were 'Your idea is strange,' 'Your idea is great for me,' and 'Your idea is my idea.' Task 3 included 10 sentences with common idiomatic expressions containing errors which could be grammatical (wrong verb form or article) or lexical (synonymous but inaccurate word). For example, 'This task was not 
difficult-it was a piece of pie!" The participants were asked to supply the correct version of the idiom. To see the complete metaphorical assessment task, see Appendix.

SECTION 3 included 15 idiomatic expressions: kick the bucket, tie the knot, blow one's top, look daggers at somebody, hit rock bottom, give somebody the cold shoulder, a wet blanket, in the crosshairs, cut corners, on the fence, black sheep of the family, play hard to get, like putty in one's hands, get hitched, ride the wave. Each idiom had four options: one literal meaning, one correct figurative meaning, and two unrelated ones. The participants were asked to pick what they believed was the correct meaning for these 15 idiomatic expressions. For example:

What does the expression 'blow one's top' mean?

$$
\begin{aligned}
& \text { a. } \text { to feel hot } \\
& b . \quad \text { to feel angry } \\
& c . \text { to feel stupid } \\
& \text { d. } \text { to be in windy weather }
\end{aligned}
$$

One goal of this assessment was to determine which idioms were already familiar to our participants and should not be taken into consideration in the analysis of the results. Furthermore, this assessment showed whether the participants were more likely to choose literal interpretations of the idioms that they were unfamiliar with (i.e., whether literal meaning was a more salient one). The hypotheses were that both ESL and EFL might favor literal meanings of the idioms over the nonliteral ones more frequently if the idioms were unfamiliar.

Not until the participants picked an option for each of the 15 idioms could they progress to the final page of the questionnaire-SECTION 4-which contained the same 15 idioms accompanied by dual-coding elucidation. The questionnaire was designed this way so that respondents could not see visuals before attempting to interpret the idioms only in verbal contexts. This helped to monitor any changes in interpretation brought about by the pictorial elucidation and ignore the idioms that were already known to the participants. A group of 9 NSs were asked to determine if the idioms could be easily associated with an image (imageable). All 9 rated the idioms as highly imageable and picked figurative meanings of the idioms (i.e., more salient ones) out of all the options provided.

SECTION 4 was designed to investigate if the mapping of figurative meaning onto literal meaning would prove an effective technique for improving the comprehension of unfamiliar imageable idioms. For this purpose, each idiom was presented in a manner which combined the verbal content from (logogens) with visual, nonverbal context (imagens), which consisted of pictorial representations of some aspects of both literal and figurative meaning (in accordance with some tenets of the dual-coding theory (Paivio, 1986). The end result is access to the correct figurative sense that is salient for all native speakers. Figure 1 shows an example of a dual-coding representation. 


\section{BLOW ONE'S TOP}

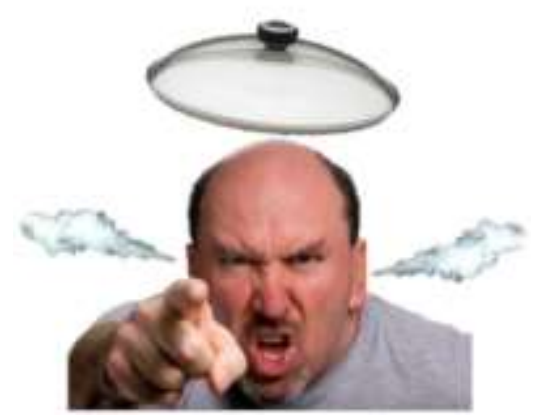

Figure 1

A Dual-Coding Representation of an Idiom 'Blow One's Top'

The author designed the questionnaire using Google Forms and used the Google image database for the visual representations of idioms. The ESL and EFL participants completed the questionnaire in their classes under the supervision of their instructors, who were given guidelines to ensure the participants did not discuss the idioms or use other extraneous help.

\section{FINDINGS}

It is important to begin with the results of SECTION 1 of the questionnaire. Due to the specific features of the ESL environment, the participants from this cohort were expected to report a larger amount of interaction with NSs and authentic media than the EFL cohort. Many of the ESL learners in this study had jobs that required them to communicate with NSs on a daily basis. This, in turn, might have had a positive effect on their metaphorical competence and language development over all. Table 1 shows the data about the participants' duration of stay in English-speaking countries and their average time spent interacting with NSs or authentic media the English language.

Table 1

Participants' Average Time in English-Speaking Countries or Their Interaction with Authentic English

\begin{tabular}{lllll}
\hline & \multicolumn{3}{l}{ ESL } & \multicolumn{3}{c}{ EFL } \\
\cline { 2 - 5 } & LMC & HMC & LMC & HMC \\
\hline $\begin{array}{l}\text { Time spent in English-speaking countries (average in } \\
\text { months) }\end{array}$ & 39 & 25 & 0.2 & 0.7 \\
\hline $\begin{array}{l}\text { Time spent interacting with NSs or authentic media } \\
\text { (average in hours per week) }\end{array}$ & 12.6 & 23.3 & 15.6 & 22.4 \\
\hline
\end{tabular}

It appears that the Russian EFL participants in this study contradicted the general expectation that they lack exposure to native L2 speakers or L2 media. Despite the absence of a lengthy experience of residing in any English-speaking countries, the EFL participants reported to have been greatly involved with authentic English media, which 
yielded the data that were quite similar to those of ESL participants'. Some of the EFL participants indicated that they regularly communicated on social media sites with people from the USA or the UK. Some had regular conversations with English-speaking pals over Skype or similar synchronous media. The terms LMC and HMC are explained below.

SECTION 2 helped to determine a tentative level of metaphorical competence of our participants using a metaphorical competence assessment task. The results of this task helped to group participants into two cohorts; thus, participants from each cohort, ESL and EFL, who correctly interpreted fewer than half of the idioms were placed into a lowlevel metaphorical competence group (LMC Group), and those who knew more than half of the idioms were placed into a high-level metaphorical competence group (HMC Group). Thus, participants were arranged into four groups: ESL LMC Group, ESL HMC Group, EFL LMC Group, and EFL HMC Group. Table 2 shows the results of the division of the ESL and EFL participants into groups according to the results of the metaphorical competence assessment.

Table 2

Participants' Placement in Groups According to the Metaphorical Competence Assessment Task

\begin{tabular}{lll}
\hline & $\begin{array}{l}\text { Low-level metaphorical } \\
\text { competence (LMC) }\end{array}$ & $\begin{array}{l}\text { High-level metaphorical } \\
\text { competence (HMC) }\end{array}$ \\
\hline ESL participants & 37 & 21 \\
\hline EFL participants & 42 & 15 \\
\hline
\end{tabular}

SECTION 3 was used to determine whether some of the idioms used in the experiment were familiar to the participants. For this purpose, all the participants were offered an idiom interpretation task which contained all the same idioms that were later used in SECTION 4. Table 3 presents the participants' choices in the idiom interpretation task from all the four groups.

Table 3

Participants' Responses to the Idiom Interpretation Task in SECTION 3 to Assess Their Comprehension of 15 English Idioms

\begin{tabular}{lllll}
\hline & LITERAL & FIGURATIVE & UNRELATED & TOTAL \\
\hline ESL LMC & $244(44 \%)$ & $56(10 \%)$ & $255(46 \%)$ & 555 \\
\hline EFL LMC & $258(41 \%)$ & $126(20 \%)$ & $246(39 \%)$ & 630 \\
\hline ESL HMC & $94(30 \%)$ & $133(42 \%)$ & $88(28 \%)$ & 315 \\
\hline EFL HMC & $38(17 \%)$ & $122(54 \%)$ & $65(29 \%)$ & 225 \\
\hline
\end{tabular}

As was hypothesized prior to this experiment, LMC learners had a larger percentage of 'literal' than 'figurative' options in both ESL (44\%) and EFL (41\%) groups. The percentage of 'unrelated' meanings was also very high for both LMC cohorts $-46 \%$ for ESL and $39 \%$ for EFL, respectively. The figurative options for the idioms were not selected as much, with $10 \%$ for the ESL and $20 \%$ for the EFL LMC participants.

Learners with higher metaphorical competence in English (HMC cohorts) opted more frequently for the correct figurative meaning of the target idioms, which was not a 
surprising finding overall. The ESL HMC group picked the figurative meaning in $42 \%$ of cases, whereas the EFL HMC group - in 54\% of cases. The HMC participants clearly did not favor the 'literal' option as much as the other groups, with 30\% in ESL and 17\% in EFL, respectively. The percentage of 'unrelated' meanings is quite large, but nonetheless is less than in the LMC groups. Figure 2 shows percentages for LMC and HMC groups (both ESL and EFL).

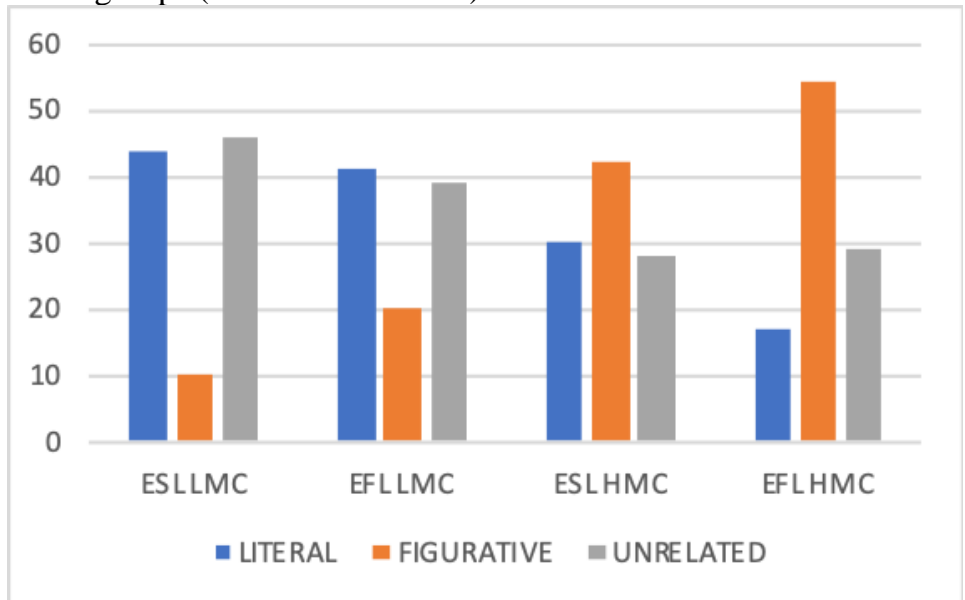

Figure 2

Percentages of All Responses in SECTION 3 of the Idiom Interpretation Task in Both LMC and HMC Groups

The results grouped not by metaphorical competence levels, but by learning environments (ESL or EFL) displays another pattern. Figure 3 shows percentages of all responses from both cohorts based on the participants' language acquisition setting.

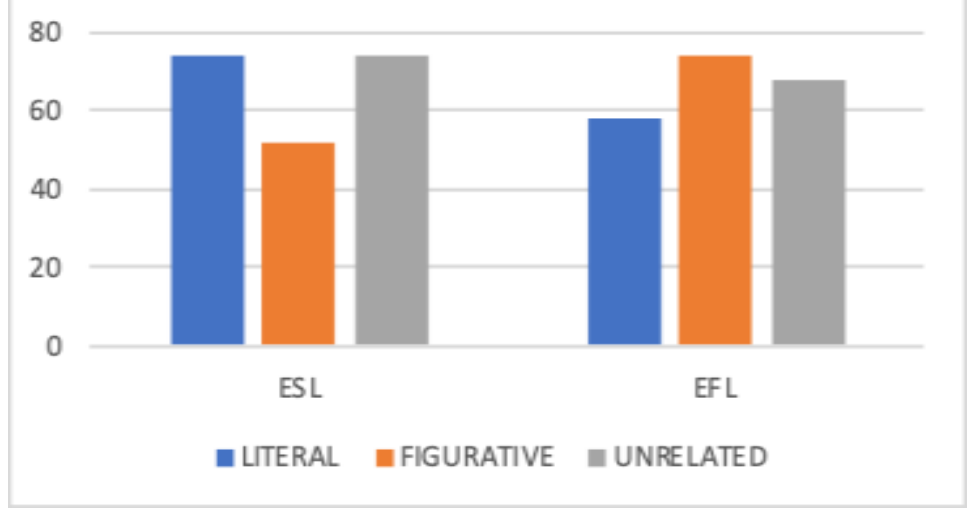

Figure 3

Percentages of All Responses in SECTION 3 of the Idiom Interpretation Task in ESL and EFL Groups 
What was at odds with the hypothesis was that the EFL cohort, all in all, demonstrated a better grasp of the presented idioms, as they correctly identified the figurative meaning of more idiomatic expressions than the ESL group (both LMC and HMC combined). In a way, this surprising finding contradicts a general expectation that the ESL environment is more conducive to a quick acquisition of nonliteral language. After all, English learners residing in English-speaking countries are often immersed in idiomaticity on a daily basis and generally have access to multiple real-life scenarios in which NSs (or NNSs) use idiomatic expressions.

A closer look at the data in Figure 3 makes it evident that of all the four groups, the EFL HMC participants had the best knowledge of the idiomatic expressions, and the ESL LMC learners - the worst. The EFL HMC group also has the fewest 'literal' choices, which again points to their good level of metaphoric competence. Figure 3 also shows a trend of correct figurative interpretation increasing and of literal interpretation decreasing from ESL to EFL learners and from low to high metaphorical competence levels.

Overall, EFL participants from each cohort demonstrated better interpretation of the idioms, which was an indication of their higher level of metaphorical competence overall. This could be explained by the fact that EFL classes tend to specifically include figurative language in the curricula. Most language textbooks include idiomatic expressions in their units as textbook authors view idiomaticity as a cornerstone of authenticity.

Lastly, the goal of SECTION 4 was to determine if the dual-coding technique could elicit more 'figurative' interpretations when the same idioms were presented with the pictorial aid. For this purpose, the participants were presented the same idiomatic expressions from the idiom interpretation task of SECTION 3, but this time the idioms were accompanied by visual representations (dual-coding elucidation). As was discussed previously, all the images were designed to combine literal components of the meaning with the figurative components, thus offerring a conceptual link between the easily understandable concrete interpretation and a more opaque figurative one. The hypothesis was that the total number of 'figurative' interpretations should increase in all groups if the idioms were elucidated by the dual-coding visuals. The results are presented in Table 5 and Figure 4.

Table 5

Interpretations of Idioms with the Dual-Coding Visual Technique

\begin{tabular}{lllll}
\hline & LITERAL & FIGURATIVE & UNRELATED & TOTAL \\
\hline ESL LMC & $176(31 \%)$ & $192(35 \%)$ & $187(34 \%)$ & 555 \\
\hline EFL LMC & $172(27 \%)$ & $283(45 \%)$ & $175(28 \%)$ & 630 \\
\hline ESL HMC & $33(10 \%)$ & $230(73 \%)$ & $52(17 \%)$ & 315 \\
\hline EFL HMC & $9(4 \%)$ & $202(90 \%)$ & $14(6 \%)$ & 225 \\
\hline
\end{tabular}




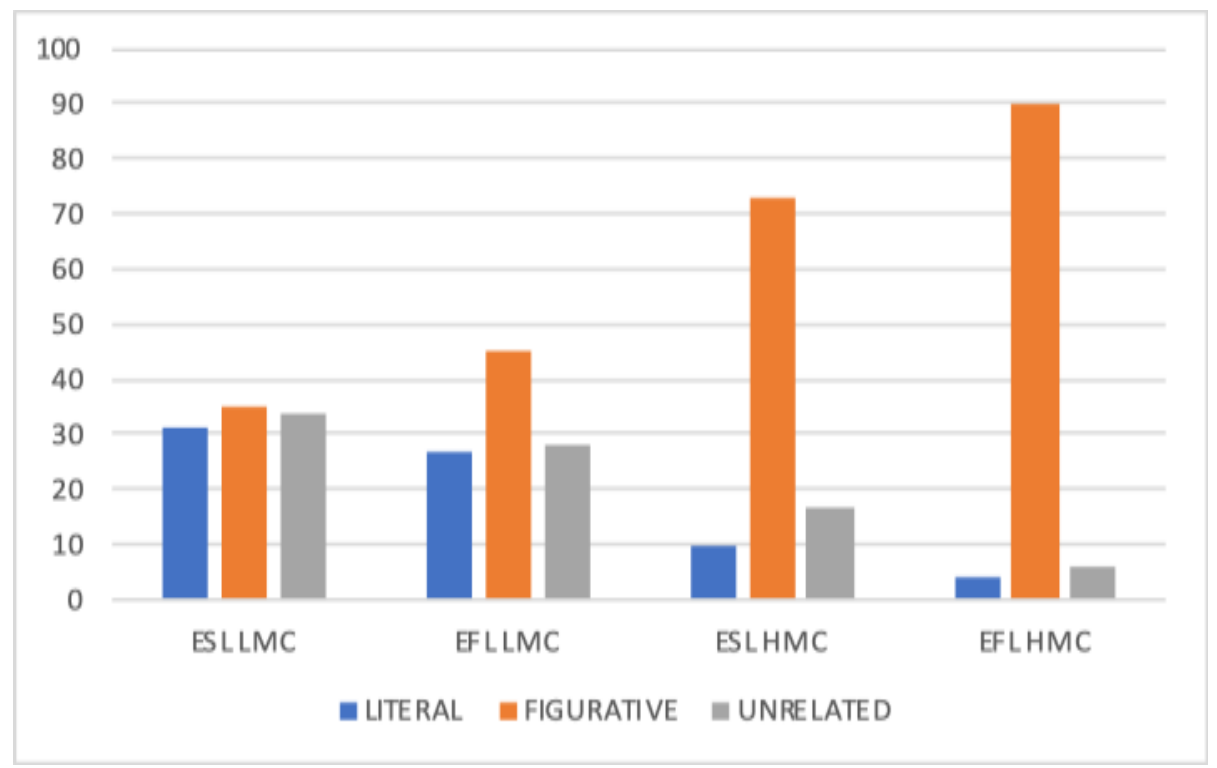

Figure 4

Percentages of All Interpretations of Idioms with a Dual-Coding Visual Technique

The data in Figure 4 show a noticeable difference from Figure 3-a change in the distribution of all three options (LITERAL, FIGURATIVE, or UNRELATED) across all groups. The data show that the visual facilitation technique improved the participants' comprehension of these unfamiliar idioms, which resulted in the increased number of 'figurative' options altogether, with the number of 'literal' and 'unrelated' options diminishing greatly.

Table 6 shows a comparison of correct figurative interpretations before and after the application of the dual-coding facilitation technique in all groups of participants.

Table 6

Results of a $t$-Test Comparing Correct Figurative Interpretations of Target Idioms with and without the Dual-Coding Support in All Groups

\begin{tabular}{|c|c|c|c|c|c|c|c|c|c|}
\hline & $\begin{array}{l}\text { Correct } \\
\text { Responses } \\
\text { Without } \\
\text { Coding }\end{array}$ & Dual- & $\mu$ & SD & $\begin{array}{l}\text { Correct } \\
\text { Responses } \\
\text { With Dual- } \\
\text { Coding }\end{array}$ & $\mu$ & SD & $d f$ & $t$ \\
\hline $\begin{array}{l}\text { ESL } \\
\text { LMC }\end{array}$ & 56 & & $\begin{array}{l}1.5 \\
1\end{array}$ & $\begin{array}{l}1.0 \\
2\end{array}$ & 192 & 5.19 & 1.13 & 36 & 13.978* \\
\hline $\begin{array}{l}\text { EFL } \\
\text { LMC }\end{array}$ & 126 & & $\begin{array}{l}3.0 \\
0 \\
\end{array}$ & $\begin{array}{l}1.1 \\
7 \\
\end{array}$ & 283 & 6.74 & 1.93 & 41 & 13.296* \\
\hline $\begin{array}{l}\text { ESL } \\
\text { HMC }\end{array}$ & 133 & & $\begin{array}{l}7.5 \\
7 \\
\end{array}$ & $\begin{array}{l}2.6 \\
9 \\
\end{array}$ & 230 & $\begin{array}{l}10.8 \\
6 \\
\end{array}$ & 2.17 & 20 & $-7.508 *$ \\
\hline $\begin{array}{l}\text { EFL } \\
\text { HMC }\end{array}$ & 122 & & $\begin{array}{l}8.1 \\
3 \\
\end{array}$ & $\begin{array}{l}2.0 \\
7 \\
\end{array}$ & 202 & $\begin{array}{l}13.4 \\
7 \\
\end{array}$ & 1.13 & 14 & $-8.177 *$ \\
\hline
\end{tabular}


A paired-sample $t$-test has demonstrated a significant difference between the number of 'figurative' interpretations before and after the implementation of the dual-coding technique in each group $(\mathrm{p}<0.001)$. The increase in 'figurative' choices is substantial in all groups, with both ESL LMC and EFL LMC participants showing remarkable improvement in comprehension (one increased more than three-fold and the other more than two-fold, respectively).

\section{DISCUSSION}

This study aimed to identify a connection between learners' exposure to authentic L2 input, their level of metaphorical competence and their ability to comprehend some visually-enhanced idioms. The traditional ESL-EFL dichotomy tends to attribute benefits to learning a language in the environment of its native speakers (Miller \& Ginsberg, 1995; Reid, 1995; Rose 1999; Brown, 2001). The data from the initial questionnaire indicated, to our surprise, that learners in the EFL environment did not appear to be disadvantaged and actually reported to have more exposure to native-like L2 than their ESL counterparts (38 and 35.9 hours per week, respectively). Thus, the immersive experience of being in a native-speaking environment is not always conducive to improvements in language proficiency since certain variables should be taken into account, such as highly interactive contacts with media and humans, the availability of comprehensible input, the availability of input made comprehensible, the availability of production practice, the availability of output made comprehensible, etc. (Longcope, 2009).

It was further illustrated that the participants' tentative levels of metaphorical competence-lower-level (LMC) or higher-level (HMC) — affected how they interpreted target idioms, with more LMC participants choosing literal interpretations of unfamiliar expressions than HMC participants in both EFL and ESL groups (see Table 3). The fact that the groups with the lowest metaphorical competence interpreted more idioms literally is not surprising and intuitively expectable because possessing metaphorical competence, as an aspect of conceptual fluency (Danesi 1995), is about knowing "how a language encodes abstract concepts on the basis of metaphorical reasoning" (Danesi, 2003 , p. 72). When this skill is underdeveloped, learners might indeed have trouble not only finding the correct meaning of an idiom but also identifying an expression as idiomatic. This finding further supports some conclusions that other researchers made on the process of L2 idiom comprehension (Kecskes, 2001, 2004; Bortfeld, 2002, 2003; Cieślicka, 2006, 2010, 2013). Language learners tend to access the literal meaning of figurative expressions first, regardless of how unfitting it may appear in the given context. This meaning is salient in their lexicons because of its ease of processing, availability, familiarity, and prototypicality (Giora, 1997, 1999, 2003). Figurative meaning is elusive and requires a good deal of knowledge about L2 speakers' way of thinking (metaphorical competence).

Additionally, EFL participants appeared to show a better overall understanding of the idioms than their ESL counterparts (Figure 3), which might show that language education overseas tends to view figurative language instruction as valuable (e.g., Maisa \& Karunakaran, 2013). 
The results of the final phase of the study clearly indicated that the application of the dual-coding technique resulted in a significant improvement in the number of correct figurative interpretations in both ESL and EFL groups of both levels of metaphorical competence. A bigger change was seen in both LMC groups (ESL LMC increased by almost 3.5 times and EFL LMC increased by 2.2 times). Note that these are the groups that had the largest number of 'literal' interpretations of idioms in SECTION 3 of the task. This led to a conclusion that the participants that were likely to interpret target idioms literally also tended to benefit most from the visual elucidation technique that presented a conceptual blend of literal and figurative meanings of those idiomatic expressions. In addition, both HMC-level groups demonstrated significant improvements in the number of correct figurative choices. This positive effect of pictorial elucidation on the comprehension of idioms in this study goes along with Boers and Lindstromberg's (2008) and Boers et al.'s (2009) findings in their experiments. The researchers also found that pictorials are effective pathways for the retention of meaning rather than form of idioms. Presenting idioms as figurative lexical chunks whose meaning is often motivated by their literal senses has long been shown by cognitive linguists as a beneficial strategy in language instruction (Littlemore, 2009; Boers \& Lindstromberg, 2008, 2009).

\section{CONCLUSION}

The main goal of this study was to investigate a facilitative effect of an instructional technique used to enhance the teaching of idiomatic expressions to learners of various amount of L2 metaphoric experience. The technique would employ both literal and figurative senses of certain idioms in a visual format. Putting all the outcomes of this study together, the following implications for language educators can be proposed:

- Learners with all levels of metaphorical competence (but especially those with a lower level of) may benefit greatly from inclusion of the literal aspects of the figurative meaning of many idioms into instruction. Of course, it is difficult to separate the effect of logogens from imagens on students' interpretation of idioms in this study; yet a combination of the literal and figurative proved to be extremely helpful.

Visualizing the figurative meaning of many idioms by way of combining the literal and the figurative aspects of their meaning enables learners to create a useful conceptual link between both, which improves their overall grasp on the correct figurative meaning.

- Students who learn English in EFL settings may often possess a robust knowledge of idiomaticity, despite a common belief otherwise. Perhaps, one explanation is that idiomatic language is of high interest to language educators and textbook authors in environments that lack native speakers.

These suggestions came out of the data in this study and could potentially enhance the efficacy of language instruction. Keeping in mind the implications of this study may prompt some educators to diversify their approach to the teaching of idiomatic expressions and utilize integrated materials specially designed for different types of learners. 


\section{Limitations}

One limitation of this study is that, while the ESL group consisted of learners of various language backgrounds, the EFL cohort only comprised speakers of Russian as a first language. It would be helpful to conduct a similar experiment with a diverse EFL cohort.

\section{Competing Interest}

The author declares that he has no competing interests in this study.

\section{Appendix}

A complete questionnaire can be found at this link - http://bit.ly/dual-coding. The is a copy of the original questionnaire: all questions are no longer 'required' for easier navigation by researchers and readers

\section{REFERENCES}

Abel, B. (2003). English idioms in the first and second language lexicon: A dual representation approach. Second Language Research, 19(4), 329-58.

Aydin, B. (2017). The effect of mental imaging technique on idiom comprehension in EFL learners. International Journal of Languages' Education, 5(4), 201-212. doi:10.18298/ijlet.2113

Begg, I., \& Paivio, A. (1969). Concreteness and imagery in sentence meaning. Journal of Verbal Learning and Verbal Behavior, 8, 821-7. http://dx.doi.org/10.1016/S00225371(69)80049-6.

Boers, F. (2000). Enhancing metaphoric awareness in specialized reading. English for Specific Purposes, 19, 137-47. http://dx.doi.org/10.1016/S0889-4906(98)00017-9.

Boers, F., \& Demecheleer, M. (2001). Measuring the impact of cross-cultural differences on learners' comprehension of imageable idioms. English Language Teaching, 55(3), 255-62.

Boers, F., \& Lindstromberg, S. (2008). How cognitive linguistics can foster effective vocabulary teaching. In F. Boers, \& S. Lindstromberg (Eds.), Cognitive linguistic approaches to teaching vocabulary and phraseology (pp. 1-61). Berlin/New York: Mouton de Gruyter.

Boers, F., \& Lindstromberg, S. (2012). Experimental and intervention studies on formulaic sequences in a second language. Annual Review of Applied Linguistics, 32, 83-110. doi:http://dx.doi.org.libezproxy2.syr.edu/10.1017/S0267190512000050.

Boers, F., Demecheleer, M., \& Eyckmans, J. (2004). Etymological elaboration as a strategy for learning idioms. In P. Bogaards, \& B. Laufer (Eds.), Vocabulary in a second language: Selection, acquisition and testing, (pp. 53-78). Amsterdam, Netherlands: John Benjamins. 
Boers, F., Eyckmans, J., \& Stengers, H. (2007). Presenting figurative idioms with a touch of etymology: More than mere mnemonics? Language Teaching Research, 11(1), 43-62. http://dx.doi.org/10.1177/1362168806072460.

Boers, F., Piriz, A. H. J., Stengers, H., \& Eyckmans, J. (2009). Does pictorial elucidation foster recollection of figurative idioms? Language Teaching Research, 13(4), 367-388. http://dx.doi.org/10.1177/1362168809341505.

Brown, H. D. (2001). Teaching by principles. New York: Longman.

Charteris-Black, J. (2002). Second language figurative proficiency: A comparative study of Malay and English. Applied Linguistics, 23(1), 104-133. doi:10.1093/applin/23.1.104.

Chen, Y., \& Lai, H. (2013). Teaching English idioms as metaphors through cognitiveoriented methods: A case in an EFL writing class. English Language Teaching, 6(6). doi:10.5539/elt.v6n6p13.

Cieślicka, A. (2006). Literal salience in on-line processing of idiomatic expressions by second language learners. Second Language Research,22(2), 115-144. doi:10.1191/0267658306sr263oa.

Conklin, K. \& Schmitt, N. (2012). The processing of formulaic language. Annual Review of Applied Linguistics, 32, 45-61. doi:10.1017/S0267190512000074.

Csábi, S. (2004). A cognitive linguistic view of polysemy in English and its implications for teaching. In M. Achard, \& S. Niemeier (Eds), Cognitive linguistics, second language acquisition, and foreign language teaching (pp. 233-56). Berlin and New York: Mouton de Gruyter.

Cuevas, J. (2016). An analysis of current evidence supporting two alternate learning models: learning styles and dual coding. Journal of Educational Sciences and Psychology, 6(1), 1-13.

Danesi, M. (1993). Metaphorical competence in second language acquisition and second language teaching: the neglected dimension. In J. E. Alatis (Ed.), Language, communication and social meaning (pp. 489-500). Washington, D.C.: Georgetown University Press.

Danesi, M. (1995). Learning and teaching languages: The role of "conceptual fluency". International Journal of Applied Linguistics, 5(1), 3-20.

Danesi, M. (1998). Sign, thought, and culture: A basic course in semiotics. Toronto: Canadian Scholars' Press.

Danesi, M. (2003). Second language teaching: A view from the right side of the brain. The Netherlands: Kluwer Academic Publishers.

Ellis, R. (1999). Second language acquisition. Oxford: Oxford University Press. 
Freed, B. (1995). What makes us think that students who study abroad become fluent? In B. Freed (Ed.), Second language acquisition in a study abroad context (pp. 123148). Philadelphia, PA: John Benjamins.

Gibbs, R., Jr. (2006). Embodiment and cognitive science. Cambridge: CUP.

Giora, R. (1997) Understanding figurative and literal language: The graded salience hypothesis. Cognitive Linguistics, $\quad 8, \quad 183-206$. http://dx.doi.org/10.1515/cogl.1997.8.3.183.

Giora, R. (1999). On the priority of salient meanings: studies of literal and figurative language. Journal of Pragmatics, 31, 919-29. http://dx.doi.org/10.1016/S03782166(98)00100-3.

Giora, R. (2003). On our mind: Salience, context, and figurative language. Oxford University Press.

Hamilton, M., \& Rajaram, S. (2001). The concreteness effect in implicit and explicit memory tests. Journal of Memory and Language, 44, 96-117.

Hoang, H., \& Boers, F. (2018). Gauging the association of EFL learners' writing proficiency and their use of metaphorical language. System, 74, 1-8. doi:10.1016/j.system.2018.02.004.

Irujo, S. (1986). Don't put your leg in your mouth: Transfer in the acquisition of idioms in a second language. TESOL Quarterly, 20(2), 287-304.

Kathpalia, S. S., \& Carmel, H. L. H. (2011). Metaphorical competence in ESL student writing. RELC Journal, 42(3), 273-290. https://doi.org/10.1177/0033688211419379.

Kecskes, I. (2000). Conceptual fluency and the use of situation-bound utterances in L2. Links \& Letters, 7, 143-158.

Kecskes, I. (2001). The graded salience hypothesis in second language acquisition. In M. Patz, S. Niemeier, \& R. Dirven (Eds.) Applied cognitive linguistics I: Language pedagogy, (pp. 249-271). Berlin/New York: Mouton de Gruyter.

Kecskes, I. (2006). On my mind: Thoughts about salience, context, and figurative language from a second language perspective. Second Language Research, 22(2), 219237. http://dx.doi.org/10.1191/0267658306sr266ra

Kecskes, I. (2010). Salience in language production. In K. Jaszczolt \& K. Allan (Eds.), Salience and defaults in utterance processing. Berlin/New York: Mouton de Gruyter.

Kecskes, I., \& Papp, T. (2000). Foreign language and mother tongue. Mahweh, N. J.

Kövecses, Z. (2002): Metaphor. A practical introduction. Oxford: Oxford University Press.

Kövecses, Z. (2005). Metaphor in culture. Cambridge: Cambridge University Press. http://dx.doi.org/10.1017/CBO9780511614408. 
Kövecses, Z. (2010). Metaphor: A practical introduction. Oxford University Press.

Kövecses, Z. (2015). Where metaphors come from: Reconsidering context in metaphor. Oxford University Press, USA.

Lakoff, G., \& Johnson, M. (1980). Metaphors we live by. Chicago, IL: University of Chicago Press.

Lantolf, J. P. (1999). Second culture acquisition. Cognitive consideration. In E. Hinkel (Ed.), Culture in second language teaching and learning. Cambridge.

Lantolf, J. P., \& Thorne, S. L. (2006). Sociocultural theory and the genesis of second language development. Oxford.

Littlemore, J. (2001). The use of metaphor by university lecturers and the problems that it causes for overseas students. Teaching in Higher Education, 6(3), 335-51. http://dx.doi.org/10.1080/13562510120061205

Littlemore, J. (2009). Applying cognitive linguistics to second language learning and teaching. Springer.

Littlemore, J. (2010). Metaphoric competence in the first and second language. Cognitive Processing in Second Language Acquisition, 293-316. doi:10.1075/celcr.13.20lit.

Littlemore, J., \& Low, G. (2006). Metaphoric competence, second language learning, and communicative language ability. Applied Linguistics, 27(2), 268-294. doi:10.1093/applin/aml004.

Liu, D. (2003). The most frequently used spoken American English idioms: A corpus analysis and its implications. TESOL Quarterly, 37, 671-700.

Llanes, A., \& Muñoz, C. (2009). A short stay abroad: Does it make a difference? System, 37, 366-379. doi:10.1016/j.system.2009.03.001.

Longcope, P. (2009). Differences between the EFL and the ESL language learning contexts. Studies in Language and Culture, 30(2), 303-320.

Maisa, S., \& Karunakaran, T. (2013). Idioms and importance of teaching idioms to ESL students: A study on teacher beliefs. Asian Journal of Humanities and Social Sciences (AJHSS), 1(1), 110-122.

Marian, V., \& Spivey, M. (2003). Bilingual and monolingual processing of competing lexical items. Applied Psycholinguistics, 24, 173-93. http://dx.doi.org/10.1017/S0142716403000092.

Miller, L. \& Ginsberg, R. B. (1995). Folklinguistic theories of language learning. In B. F. Freed (Ed.), Second language acquisition in a study abroad context (pp. 293- 317). Philadelphia: John Benjamins.

Milton, J., \& Evans, V. (2000). A good turn of phrase - advanced idiom practice. Express Publishing. 
Paivio, A. (1971). Imagery and verbal processes. New York: Holt, Rinehart, and Winston.

Paivio, A. (1986). Mental representations: A dual coding approach. Oxford. England: Oxford University Press.

Paivio, A., \& Begg, I. (1970). Imagery and comprehension latencies as a function of sentence structure and concreteness. Research Bulletin No. 154, Department of Psychology, University of Western Ontario.

Paivio, A., \& Csapo, K. (1973). Picture superiority in free recall: Imagery or dual coding? Cognitive Psychology, 5, 176-206. http://dx.doi.org/10.1016/0010$0285(73) 900327$.

Paivio, A., Yuille, J. C., \& Madigan, S. A. (1968). Concreteness, imagery, and meaningfulness for nouns. Journal of Experimental Psychology, 76(1). http://dx.doi.org/10.1037/h0025327.

Reid, J. M. (1995). Learning styles in the ESL/EFL classroom. Heinle \& Heinle Publishers, International Thomson Publishing Book Distribution Center.

Rose, K. R. (1999). Teachers and students learning about requests in Hong Kong. In Culture in second language teaching and learning. Cambridge: Cambridge University Press.

Rizq, W. M. (2015). Teaching English idioms to L2 learners: ESL teachers' perspective. St. Cloud University.

Sadoski, M. (2005). A dual coding view of vocabulary learning. Reading \& Writing Quarterly, 21(3), 221- 238.

Sadoski, M., \& Paivio, A. (2013). Imagery and text: A dual coding theory of reading and writing. Taylor and Francis Group. New York and London.

Schmidt, R. (1990). The role of consciousness in second language learning. Applied Linguistics, 11, 129-158. http://dx.doi.org/10.1093/applin/11.2.129.

Schmitt, N. (2000). Vocabulary in language teaching. Cambridge, England: Cambridge University Press.

Spivey, M. J., \& Marian, V. (1999). Crosstalk between native and second languages: Partial activation of an irrelevant lexicon. Psychological Science, 10, 281-84. http://dx.doi.org/10.1111/1467-9280.00151.

Verspoor, M., \& Lowie, W. (2003). Making sense of polysemous words. Language Learning, 53, 547-86. http://dx.doi.org/10.1111/1467-9922.00234.

Wray, A. (1999). Formulaic language in learners and native speakers. Language Teaching, 32(4), 213-231. doi:10.1017/S0261444800014154.

Wray, A. (2000). Formulaic sequences in second language teaching: principle and practice. Applied Linguistics, 21(4), 463-489. doi:10.1093/applin/21.4.463. 
Yuille, J. C. \& Paivio, A. (1969). Abstractness and the recall of connected discourse. Journal of Experimental Psychology, 82, 268-72. http://dx.doi.org/10.1037/h0028373. 